\title{
Correction to: A security risk perception model for the adoption of mobile devices in the healthcare industry
}

\section{Alex Alexandrou ${ }^{1} \cdot \mathrm{Li}^{-C h i o u} \mathrm{Chen}^{2}$}

Published online: 5 December 2019

○) Springer Nature Limited 2019

\section{Correction to: Security Journal (2019) 32:410-434 https://doi.org/10.1057/s41284-019-00170-0}

Unfortunately, the co-author's affiliation was wrongly published in the original online publication of this article. The correct affiliation should read as:

Li-Chiou Chen, Department of Information Technology, Seidenberg School of Computer Science and Information Systems, Pace University.

Publisher's Note Springer Nature remains neutral with regard to jurisdictional claims in published maps and institutional affiliations.

The original article can be found online at https://doi.org/10.1057/s41284-019-00170-0.

Alex Alexandrou

aalexandrou@jjay.cuny.edu

1 Department of Security, Fire, and Emergency Management, John Jay College of Criminal Justice, 524 W. 59th St, New York, NY 10019, USA

2 Department of Information Technology, Seidenberg School of Computer Science and Information Systems, Pace University, New York, USA 